\title{
HIGIENE, VIVIENDA Y CIUDAD: CIFRAS, IMÁGENES Y PALABRAS FEMENINAS
}

\author{
ANDRÉS MARTÍNEZ MEDinA \\ Universidad de Alicante
}

Recibido 09/02/2011

Aceptado 20/05/2011

\section{Resumen}

¿Qué forma final tenía el proyecto de la Modernidad, iniciado en el siglo XVIII? No es relevante. Aquí se desgrana la trayectoria de mujeres que desde sus profesiones influyeron decisivamente en la arquitectura. Se constata que estas aportaciones se realizaron desde países con Democracia donde se favorecía la libertad individual, la educación y la independencia económica; es decir: donde la responsabilidad se depositaba en función de la capacitación. Tres ámbitos de estudio: la higiene, la vivienda y la ciudad a lo largo de los siglos XIX y XX. La primera protagonista es la fundadora de la Enfermería que sienta los principios de la higiene a partir de la experiencia traducida a cifras. La segunda es una serie de diseñadoras y editoras que se interesaron por los nuevos modos de vivir que se ensayaron en USA a mitad de siglo XX, apostando por las imágenes. La tercera es una periodista que reflexionó en torno al urbanismo que se estaba dando en dicho periodo, sintetizando su pensamiento en un libro. Una reflexión entorno al poder de las cifras, las imágenes y las palabras.

Palabras clave: Arquitectas, Ciudad, Vivienda, Higiene, Democracia 


\begin{abstract}
What form had the Modernity initiated from the eighteenth century? It isn't relevant. In this article I analyze the path of women who had a decisive influence on architecture from their professions. It is noted that these contributions were made in countries where Democracy favoured individual freedom, formation and economic independence, that is: where responsibility is placed on the training function. The three areas of study are: health, housing and city throughout the nineteenth and twentieth centuries. The first protagonist is the founder of nursing that sets out the principles of hygiene from experience translated to numbers. The second one is a series of designers and publishers were interested in new ways of living that were tested in the U.S. mid-twentieth century resting the pictures. The third one is a reporter who reflected the urban environment that was taking place in this period, synthesizing her though in a book. It's a reflection about the numbers, the pictures and the words.
\end{abstract}

Keywords: Women Architects, Cities, Houses, Hygiene, Democracy 


\section{Mujeres en la Historia: la responsabilidad por capacitación}

El primero de enero de 2011 tomaba posesión Dilma Rosseff como Presidenta de Brasil. Relacionar los méritos de las mujeres que han ocupado cargos de responsabilidad en la toma de decisiones que afectan a amplios segmentos sociales $-\mathrm{y}$ los cuales no procedan por razón hereditaria-, o han desarrollado tareas creativas, no es el objeto de este trabajo, ya que todas y todos tenemos en mente una amplia lista al respecto. Sin embargo, sí pretendemos constatar que este listado se incrementó desde que se redactaron en 1776 la Constitución de Derechos de Virginia y en 1791 la Declaración de los Derechos de la Mujer y la Ciudadana, esta última, obra de M. O. de Gouges. Resulta más interesante comprobar cómo este aumento corre en paralelo a la implantación de la Democracia como forma de gobierno de las sociedades, de manera que se intuyen relaciones entre los sistemas políticos que fomentan la libertad individual y el incremento de las mujeres en tareas reservadas a los hombres. Esta presencia se extiende a casi todas las disciplinas y trabajos.

La democracia ha traído, desde su reinvención a finales del siglo XVIII, más libertad. Este es un proceso vivo, un camino del que desconocemos el final, cuyo recorrido hasta la fecha constata que su despliegue ha concatenado la consecución de derechos para los seres como personas no del todo previstos en un principio. De algún modo, paulatinamente, se ha alcanzado un cierto orden $\sin$ plan $^{1}$ y, este proceso, que se retroalimenta sin fin, ha permitido que las mujeres alcancen la misma legitimidad que los hombres y que, desde entonces, otra mirada y otro modo de hacer se instaure en las propias sociedades. Especialmente en las occidentales, donde el grado de evolución de las democracias está muy elaborado. Claro que no sólo de libertad vive la democracia, la primera también se alimenta de otros dos pilares casi incuestionables: la posibilidad de la independencia económica de las personas (sean del género que sean) y de la posibilidad de acceso a una educación que forme

1. Esta expresión reproduce parte del título del libro de INFANTINO, Lorenzo. El orden sin plan. Las razones del individualismo metodológico [1998]. Madrid, Unión Editorial, 2000, en el cual se mantiene la tesis según la cual el ente «sociedad» tiende a autorregularse y su acción no se puede separar de la acción de sus individuos. 


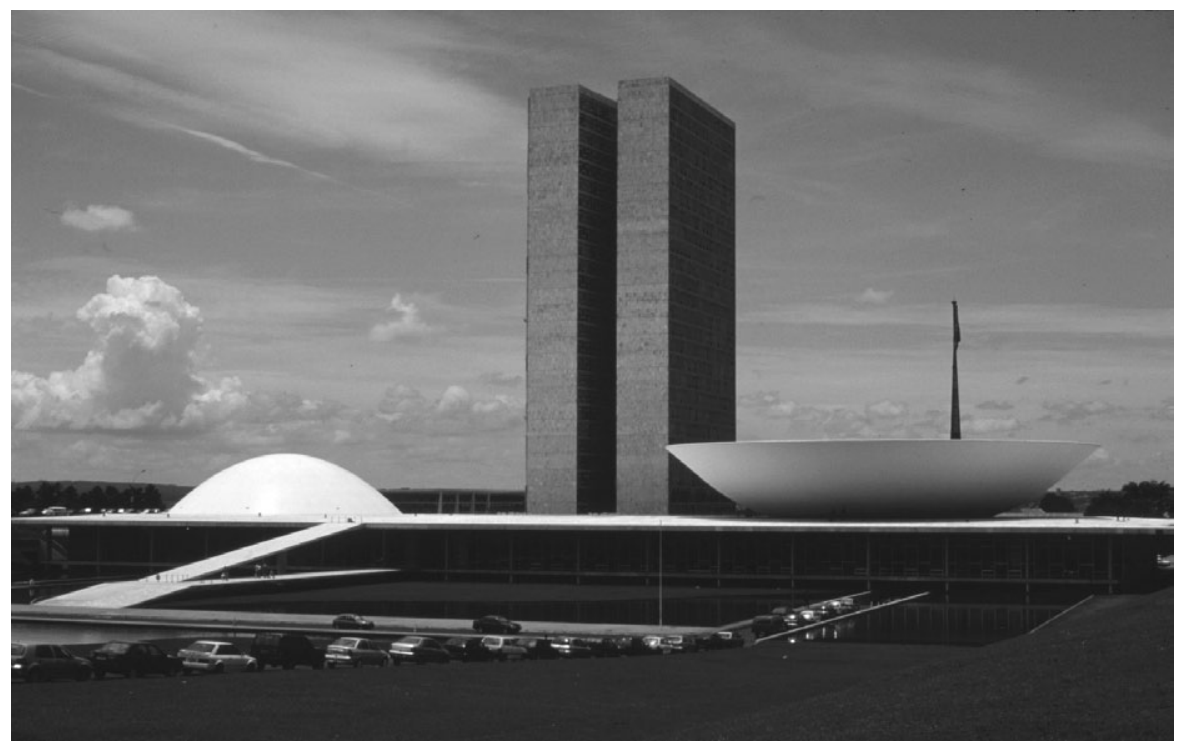

Plaza de los Tres Poderes y Congreso Nacional. Brasilia. Oscar Niemeyer (1957-58).

a las personas para poder desarrollar todas sus capacidades en plenitud. A nuestro juicio, no existe libertad sin independencia económica y sin criterio formado libre y ampliamente.

Si hemos comenzado por la Presidenta de un país donde se cruzan razas, religiones, lenguas y muchas otras excusas que hasta hoy han sido motivo de discriminación o exclusión, lo es tanto por estos hechos cuantitativos como por el cualitativo y simbólico de que la ceremonia tuviera lugar en el edificio del Congreso de la ciudad de Brasilia (1957-59); el primero obra de O. Niemeyer y la segunda obra de L. Costa y el mismo O. Niemeyer. Ambos conjuntos, enlazados en la plaza de los Tres Poderes, han representado, en algún momento, un ejemplo de la culminación del «proyecto moderno», donde una nueva arquitectura desencadenaría una nueva ciudad que, con toda probabilidad, desembocaría en una nueva sociedad Dudamos que el futuro se pueda dirigir como si nos encaminásemos hacia una utopía, siquiera de bases científicas, ni que la modernidad tenga un modelo predefinido de arquitectura y de ciudad. Ambas se definen en cada tiempo para cada espacio y grado de desarrollo político y económico y al fin social, porque la arquitectura, como la ciudad, son construcciones sociales, como principio y como fin. 
Lejos de iniciar un debate sobre si la modernidad finalizó y a esta le sucedió la posmodernidad o sobre si el proyecto de la modernidad fue bien interpretado en el ámbito de la arquitectura y el urbanismo (si es que había tal proyecto en su inicio), nos resulta más sugerente rastrear el camino de una serie de mujeres que, trabajando al lado de la arquitectura, contribuyó a mejorarla desde los ámbitos de sus específicas profesiones. No creemos que sea casualidad que las protagonistas elegidas se desenvuelvan -no sin cierta dificultad- en países con una democracia bastante desarrollada, con un sistema económico liberal, con un amplio grado de libertad de prensa, con un sistema educativo que, poco a poco, alcanzaba a capas sociales más amplias y donde era posible su independencia económica, la que garantizaba su libertad de acción. Este periplo, que barre los cien años que van desde mediados del siglo XIX a mediados del XX, se detiene en tres disciplinas: la higiene (o la enfermería), la vivienda (o lo doméstico) y la ciudad (o la convivencia). Dos de estos ámbitos resultan cruciales en las cuestiones de género, como señala Zaida Muxí: «la escenificación y puesta en práctica de roles tiene dos espacios: la casa y la ciudad $»^{2}$. Todas estas aportaciones han ayudado a dignificar el ámbito donde vivimos, en la salud y en la enfermedad, en la vivienda y en la ciudad. Es decir, forman parte del proceso de modernización de nuestra sociedad. Si la modernidad la identificamos con una mejora de las condiciones de vida, incluiría, necesariamente, el respeto y consideración entre todos los seres humanos.

\section{Las enfermedades en el ámbito de la higiene o el poder de las cifras}

Vida es sinónimo de salud. Salud es ausencia de enfermedad o a la inversa: las enfermedades son la carencia de una completa salud. Salud y enfermedad puede que sean opuestos, pero no contrarios. Algunas enfermedades mantienen una cierta vecindad con la muerte: algo de muerte tiene la enfermedad. Y la muerte vuelve iguales a todos los seres humanos, quizás porque dejan de serlo. Las enfermedades tienen la misma antigüedad que la propia vida: se tiene conocimiento de la existencia de enfermedades desde los albores de la Humanidad y, para curarlas -entre otros menesteres-, surgieron brujos, hechiceras y chamanes ${ }^{3}$. Ellos y ellas intentaban reponer las fuerzas (físicas) y el ánimo (espiritual) que las enfermedades habían mermado en el cuerpo,

2. Muxí, Zaida: «Decir la ciudad desde la experiencia». Arquitectos, nº 2, (2006), Madrid, pp. 53-58.

3. Todavía, a comienzos del siglo XX, los nativos de Nigeria con quienes trataba la misionera Mary Slessor (1848-1915), natural de Escocia, la llamaban «la bruja blanca» por su fama de sanadora. 


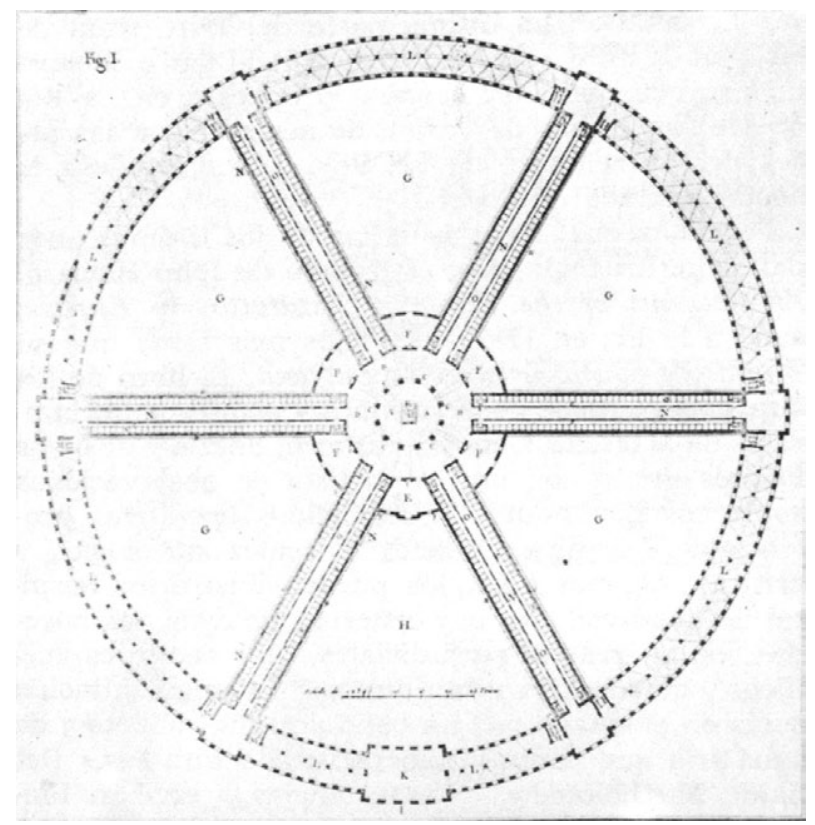

Planta hospital Hôtel-Dieu en París. Antoine Petit (1774).

en la cabeza o en el corazón. No sería de extrañar que una de las primeras arquitecturas fueran primitivos hospitales: cabañas donde alojar a los enfermos para separarlos de los sanos.

El trayecto que nos sitúa a finales del siglo XVIII, en plena efervescencia intelectual en la que se fraguan las dos grandes revoluciones sociales citadas que instauran los derechos del hombre (y de la mujer) no es relevante para la higiene. Sí lo es que en aquellos años de derroche de racionalidad, los mismos criterios que emanaban de la ciencia se pretendían aplicar para resolver los problemas formales y funcionales de la arquitectura. Cuestiones de tipología: encontrar los mejores encajes de las formas -conocidas o experimentables-a las funciones o viceversa: acoplar de modo óptimo el contenido al contenedor. Uno de los debates que reunía a profesionales de la arquitectura y de la medicina era el del diseño de hospitales. Ambas disciplinas - una menos científica que la otra- estaban siendo sometidas a profundos cambios, muchos de ellos de base empírica.

A lo largo del setecientos fueron formulados dos tipos arquitectónicos para solucionar funcionalmente los hospitales. Por un lado estaba el modelo radial con salas partiendo desde su centro (donde se encontraba la capilla), el 


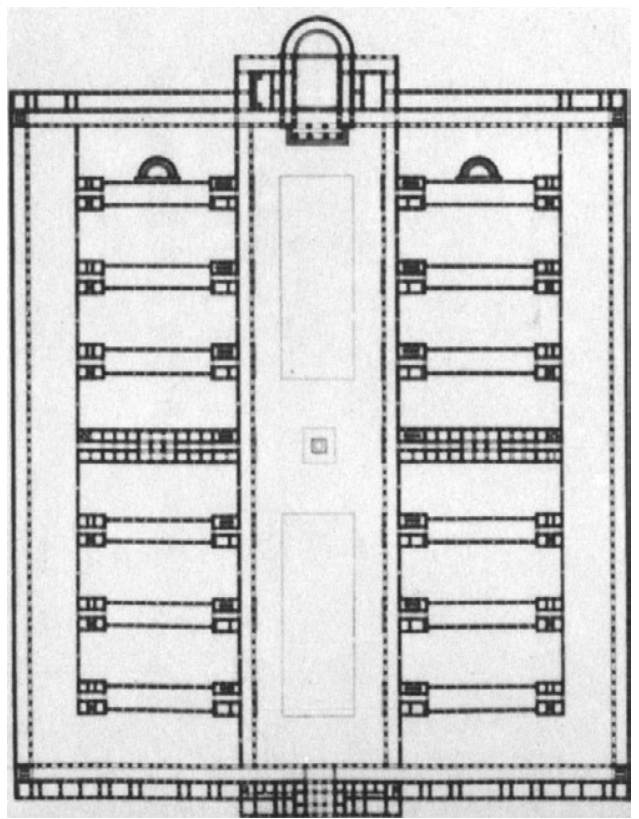

Planta hospital en La Roquette, París. J.R. Tenon y B. Poyet (1788).

cual permitía «más camas en una misma superficie» ${ }^{4}$; estaría representado por el proyecto del Hôtel-Dieu (1774) en París. Por otro lado estaba el modelo de pabellones dispuestos perpendicularmente a ambos lados de un patio alargado (con la capilla situada al final del eje); estaría representado por el proyecto de un hospital en La Roquette (1788), también en París, que venía avalado por científicos, cirujanos y arquitectos. En esos años ya se pensaba que la falta de ventilación de las salas se encontraba relacionada con las muertes de los ingresados en dichas instituciones.

El debate no quedó zanjado y los hospitales existentes tendían a colmatar sus espacios libres y a densificarse en altura, sin que las intuitivas ventajas higiénicas de ambos modelos pudieran surtir efecto. A mediados del siglo XIX, el Hospital Militar de Netley (1856-63) de Londres presentaba unas condiciones infrahumanas y unos altos índices de mortandad. Florence Nightingale (1810-1910) hizo de este centro sanitario -al que no consideraba tal- su objeto de lucha: «quería que fuera demolido, tan rápido como había

4. Pevsner, Nikolaus. Historia de las Tipologías Arquitectónicas [1976]. Barcelona, ed. Gustavo Gili, 1979, p. 173. 


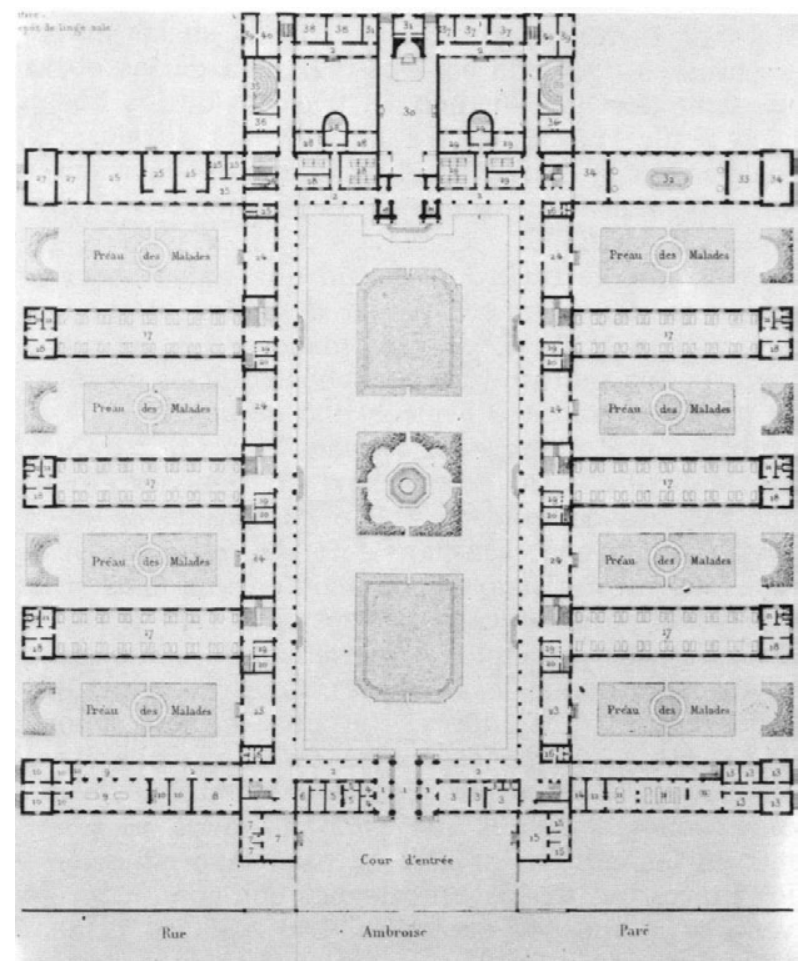

Planta hospital Lariboisière, París. M.P. Gautier (1839-1854).

sido construido y que fuera reemplazado por otro edificio según el tipo de proyecto de Lariboisière» ${ }^{5}$ (1839-54) de París que seguía el modelo pabellonario. Nightingale argumentaba razones de índole científica basadas en «la experiencia, la observación y la reflexión $»^{6}$. Señalaba que en los hospitales de pabellones «las salas estaban especialmente diseñadas para recibir la luz y el aire fresco, al tiempo que permitían que los 'efluvios malignos' o 'miasmas' pudieran disiparse entre los largos y estrechos bloques» ${ }^{7}$.

Florence Nightingale, nacida en Florencia en el seno de una rica familia británica, ya desde pequeña se había sentido atraída por el cuidado de

5. PEVSNER, Nikolaus. Op. cit., p. 184.

6. AtTEWELL, Alex. «Florence Nightingale (1820-1910)». Perspectivas: revista trimestral de educación Comparada, vol. XXVIII, n 1, 1998, París, pp. 173-189; también disponible en: <http://www.ibe.unesco.org/publications/Thin-kersPdf/nightins.PDF> pp. 1-13 (2011.02.01).

7. AtTEWell, Alex. Op. cit., p. 5. 
enfermos (y también por la enseñanza), si bien se formaría primero en matemáticas, aunque a ambos conocimientos se opusieron sus padres. A mediados del siglo XIX la enfermería no era considerada una profesión adecuada para una mujer de su posición, era propia de mujeres pobres. Aún así, a los 24 años comenzó a visitar centros asistenciales, aunque el estudio de los sistemas hospitalarios se fraguó entre 1849 y 1853 en distintos viajes que le llevarían de Europa a Alejandría, formándose como enfermera en Dusseldorf y en Saint Germain cerca de París ${ }^{8}$. A su regreso a Londres en 1853, Nightingale se convirtió en la directora de un sanatorio para damas de la alta sociedad londinense.

Su fama de profesional rigurosa -observadora y organizadora- la llevaría a estar al frente de las instalaciones sanitarias en Üsküdar por la Guerra de Crimea (1854-56). Las condiciones antihigiénicas de los hospitales de campaña eran tales que existía una probabilidad siete veces mayor de morir en estas instalaciones de cualquier enfermedad que de morir en el campo de batalla. Allí aplicó lo que consideró principios de la higiene (o leyes de la salud) para combatir las epidemias de cólera y disentería, basados en la limpieza, la ventilación, la iluminación, el empleo de agua potable y una alimentación sana (de frutas y productos frescos). Recolectó datos que, más tarde, se volverían estadísticos. Las matemáticas se volvieron «sanadoras» cuando Nightingale usó las cifras. Sus cálculos demostraron que una mejora en los medios higiniestas empleados disminuía el número de muertes (redujo la tasa de mortalidad en porcentajes considerables). Estas informaciones serían herramientas para mejorar los hospitales urbanos.

Al volver a Londres en 1856, Nightingale descubrió que, en época de paz, los soldados de entre 20 y 35 años tenían una tasa de mortalidad que doblaba a la de los civiles. Usando sus datos ilustró la necesidad de una reforma sanitaria en todos los hospitales, comenzando por los militares. Fue una experta estadística y una pionera de la epidemiología, coincidiendo con el descubrimiento de los gérmenes de Louis Pasteur (1858). En 1860 abrió la primera Escuela de Enfermería en Londres, logrando transformar la mala fama de esta dedicación en una carrera responsable y respetable para las mujeres. Aunque pasó el resto de su vida postrada, la enfermedad no la detuvo en hacer campaña para mejorar los estándares de salud. Publicó 200 libros entre los que destacan: Notas sobre los hospitales (1959), Notas sobre enfermería (1860) y Notas sobre enfermería para las clases trabajadoras (1861); estos últimos específicos

8. Ibíd., p. 174.

Feminismo/s 17, junio 2011, pp. 229-257 
para la enseñanza de la enfermería y traducidos a varios idiomas. Su método se resume en sus propias palabras de 1882:

«La observación indica cómo está el paciente; la reflexión indica qué hay que hacer; la destreza práctica indica cómo hay que hacerlo. La formación y la experiencia son necesarias para saber cómo observar y qué observar; cómo pensar y qué pensar»".

Florence Nightingale se convertiría en la fundadora de la actual Enfermería, sentando las bases científicas de la higiene y profesionalizando la formación del personal desde una perspectiva laica. No fue un caso aislado en el panorama del diecinueve, sino que ayudó a consolidar la gran corriente higienista que atravesó el siglo y puso en contacto a diferentes disciplinas para que colaborasen entre ellas -allí donde se necesitaban- desde presupuestos científicos y racionales. De alguna manera, la primera de las enfermeras de la era Contemporánea nos igualó a todas las personas ante la enfermedad y la muerte, al sistematizar experimentalmente los requerimientos que habían de reunir los espacios sanitarios para mejorar la salud y definiendo la higiene, que ya entraría a formar parte de las ciencias médicas al tiempo que estas se revolucionaban con los descubrimientos del micromundo. Obviamente, el papel desempeñado por Nightingale es difícil de imaginar sino se suman, a su posición adinerada (que le permitía la independencia económica) y personalidad (de fuertes convicciones procedentes de la experiencia), las condiciones de una sociedad liberal que, poco a poco, avanzaba en la consecución de derechos individuales basados en la valía y cualificación profesional. Los números, aunque estadísticos, tuvieron razón y repercutieron en los espacios y organizaciones de las arquiecturas hospitalarias.

\section{Las viviendas en el ámbito de lo doméstico o el poder de la imagen}

El hábitat. La vivienda. La casa. Probablemente el primer hogar cubierto hecho con las manos humanas fue una cabaña: una tienda móvil o una choza fija. Casa deriva del mismo término latino y significa choza, cabaña. Estas primitivas arquitecturas, como las actuales, tenían un exterior, que protegía, y un interior, que cobijaba y acogía la familia. Un exterior acorazado y un interior doméstico. «Mi casa es mi castillo» escribiría en 1919 Alvar Aalto sobre el porche de la casa de sus padres ${ }^{10}$. «La casa es una máquina de habitar»

9. Florence Nightingale citada en: AtTEWELl, Alex. Op. cit., p. 9.

10. Zabalbeascoa, Anatxu; RodríGuez Marcos, Javier. Vidas construidas, biografías de arquitectos. Barcelona, ed. Gustavo Gili, 1998, p. 221. 
afirmaría cuatro años después Le Corbusier ${ }^{11}$. La mayoría de los antropólogos coinciden en que la choza se ancló al terreno con el descubrimiento y dominio de la agricultura, una actividad que transcurre a ras de suelo. El hábitat se hizo casa en el campo, vinculándose a la tierra. Quizás por ello, frente al sentido de verticalidad inherente a la casa que apunta el filósofo G. Bachelard ${ }^{12}$, cabría -en origen- la visión de la casa como un ser horizontal, posada y reposada, vinculada con su entorno inmediato: el jardín, el huerto, el campo... junto a una naturaleza domesticada. Y doméstico deriva de domus -casa-, es lo que se domina desde la casa o queda bajo su ámbito. Cuando las casas estaban encerradas tras los muros, se abrían a un patio interior -que miraba al cielo- donde habitaba una menuda fracción de naturaleza, como lugar de descanso -jardín- o como fuente de alimento -huerto-. Cuando se derribaron los muros, el espacio del hogar se expandió a su alrededor para conquistar su entorno. Nadie mejor que el arquitecto Wright supo pulverizar los ciegos muros e invertir estos términos en el ámbito de lo doméstico: lo vertical vuelto horizontal y el interior vuelto exterior atrayendo la naturaleza, intentando devolver el equilibrio primitivo.

La publicación de las Prairie House de F. Lloyd Wright (1867-1959) en los primeros años del siglo XX en revistas de $"$ Casas» ${ }^{13}$ para la clase media-alta estadounidense revolucionó el ámbito de lo doméstico en lo material, no en lo social ${ }^{14}$. El éxito de estas viviendas unifamiliares aisladas, cuyos programas se desplegaban mayoritariamente en planta baja, emplazadas en suburbios

11. LE CORBUSIER. Hacia una arquitectura [1923]. Barcelona, ediciones Apóstrofe, 1998, p: XXXI.

12. BACHelard, Gaston. La poética del espacio [1957]. México, ed. Fondo de Cultura Económica, 2010, p. 48: «La casa es imaginada como un ser vertical», «La casa es imaginada como un ser concentrado» y «...se puede oponer la irracionalidad del tejado a la irracionalidad del sótano».

13. FRAMPTON, Kenneth. Historia crítica de la arquitectura moderna [1980]. Barcelona, ed. Gustavo Gili, 1998, p: 60. El nombre de Wright llegó hasta el extremo que la revista Ladies' Home Journal le encargó entre 1900 y 1901 que proyectara viviendas-tipo para esta "clase media» americana a fin de difundirla entre sus lectoras.

14. WATSON, Peter. Historia intelectual del siglo XX [2000]. Barcelona, ed. Crítica, 2007, pp: 233-236, cita a los sociólogos Robert y Helen Lynd que realizaron un estudio modélico en una ciudad «media» que definía la sociedad americana hacia la década de 1920 y que denominaron Middletown (en la actualidad Muncie, Indiana). Allí constataron que, a diferencia de Europa donde se consideraba que existían tres clases sociales (alta, media y baja), en USA sólo se detectaban dos clases: la empresarial y la trabajadora. Descubrieron también que los cambios en las conductas sociales eran más rápidos en relación a lo material que a lo social: «Los cuartos de baño y la electricidad han invadido los hogares de de la ciudad de forma más rápida que las innovaciones relativas a la vida marital o al trato de padres e hijos. El automóvil ha cambiado las ocupaciones del tiempo libre...». El estudio completo se recogió en los libros: Middletown: A Study in 


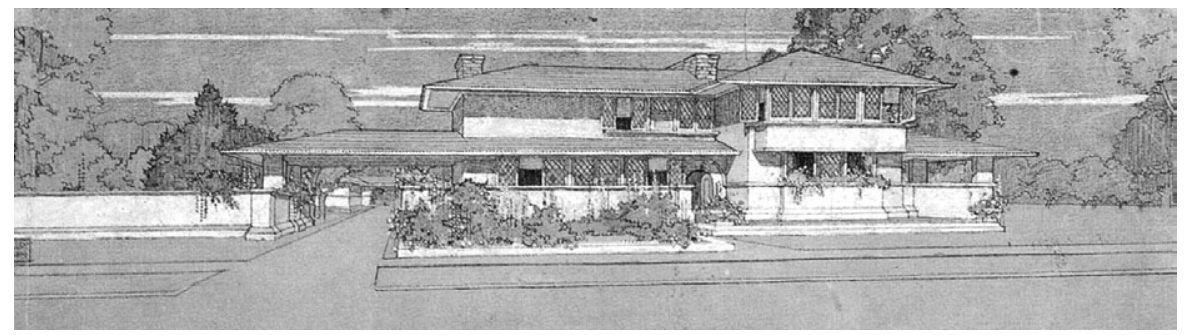

Perspectiva de casa para el Ladies' Home Journal. F. Ll. Wright (1901).

jardín de las metrópolis americanas se debía, entre otras razones, a la estrecha relación que establecían sus interiores con el jardín circundante (para su disfrute estético), el cálido tratamiento de los espacios que basculaban alrededor de una o varias chimeneas, la tranquilidad que transpiraban sus interiores y la funcionalidad de sus distribuciones (que, en muchos casos, incluían el acceso en coche); un buen ejemplo de todo ello se resume en la casa A. Coonley en Riverside (1907-09). Uno de los aspectos significativos del trabajo de Wright fue que contaba con mujeres en su equipo de técnicos (como la ceramista Catherine Ostertag), más sensibles en la creación de atmósferas íntimas y a la vez abiertas, así como el hecho de que solía prestar más atención a las esposas de sus clientes que a ellos mismos, ya que las consideraba las auténticas usuarias y conocedoras de los ámbitos domésticos de las viviendas.

$\mathrm{Su}$ idea sobre la arquitectura, bastante peculiar y receptiva a múltiples influencias, debió ampliarse con las aportaciones de sus colaboradoras y sus clientas que lo defendían ${ }^{15}$. Wright no imaginó la trascendencia e influencia que acarrearía para toda la arquitectura europea (de vanguardia o no) del momento y posterior, tras la exposición de su obra en Berlín y su publicación por E. Wasmuth en 1910. El poder de la impresión de estas arquitecturas mediante planos y fotografías se revelaba en la capacidad de convicción de las imágenes por lo que evocaban, evidenciando que una imagen valía más que mil palabras. Seguramente uno de los arquitectos europeos contemporáneos más receptivos a su sentido de fluidez espacial y su prolongación en la naturaleza sería el alemán Ludwing Mies van der Rohe (1886-1969), si bien las interpretaciones de este quedaban bajo la órbita de las rupturistas vanguardias del viejo continente y sus propuestas, además de radicalmente geométricas y

Contemporary American Culture (1929) y Middletown in Transition (1937). Y las «casas» pertenecen a lo material.

15. Zabalbescoa, Anatxu; Rodríguez Marcos, Javier. Vidas construidas... Op. cit., p. 128. 


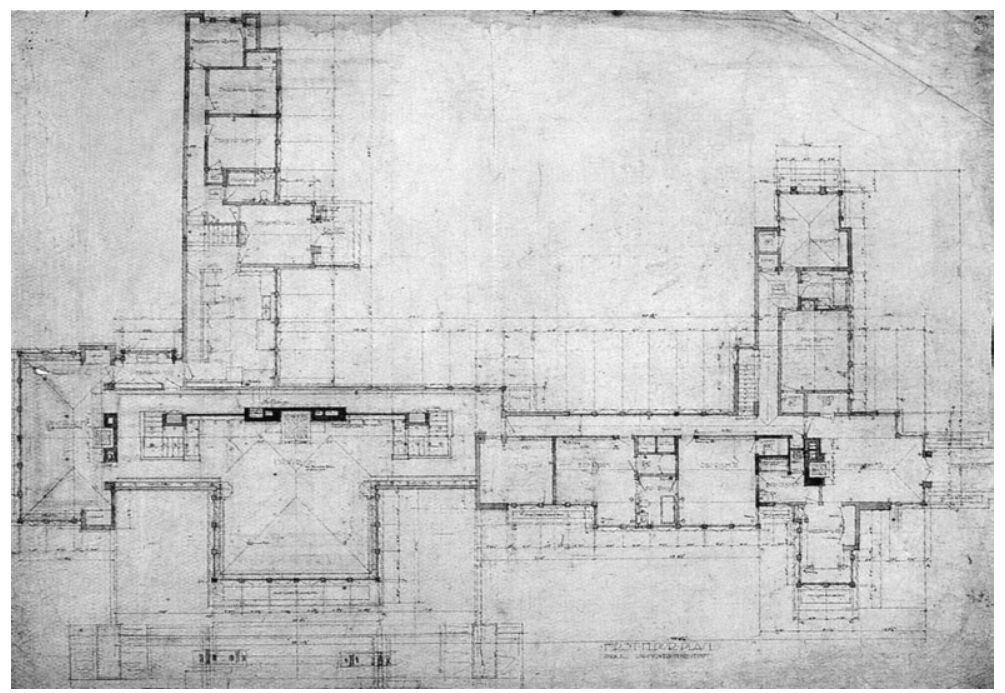

Planta casa A. Coonley, Riverside (Illinois). F. Ll. Wright (1907-09).

tendendes a la disolución de la materia, establecían un diálogo con el entorno natural sobre el que o no se intervenía o se hacía lo mínimo. La cena de bienvenida de Mies a USA fue presidida por Wright (Mies fue el único de los maestros europeos recibidos por el patriarca), con lo que, si bien entre sus arquitecturas $-\mathrm{y}$ entre ellos- hubieron diferencias, también son patentes las deudas y el parentesco. Y además: «Mies influyó tanto en los Estados Unidos como los Estados Unidos influyeron en él ${ }^{16}$, incluida la arquitectura.

Entre la visita de Wright al viejo mundo (1909) y la emigración de Mies al nuevo continente (1937), tiene lugar una de las más significativas aportaciones de la arquitectura contemporánea al campo de la vivienda y al universo de lo doméstico, bajo la órbita de los principios científicos de la vanguardia de la Nueva Objetividad. La vivienda en Europa no tenía el mismo tipo de planteamiento que al otro lado del Atlántico; aquí los problemas de falta de viviendas, su nivel de equipamiento e instalaciones, sus condiciones de salubridad e higiene, su superficie habitable, su calidad constructiva y su precio (en alquiler o en propiedad), provocó que los experimentos vivaran más hacia lo social y lo urbano que hacia las lúdicas relaciones del interior con el exterior, propios de una sociedad más opulenta, con mayor nivel de riqueza tanto en lo material como en lo temporal (una incipiente sociedad del ocio). En Europa se

16. Íbid., p. 192. 
derivó más hacia la agrupación colectiva mientras que en USA la cuestión era de individualidad. En las numerosas investigaciones teóricas (exposiciones, publicaciones, congresos...) y prácticas (casas, edificios, barrios...) también participaron arquitectas y diseñadoras. Entre ellas destacarían Eileen Gray (1878-1976), Margarete Schütte-Lihotzky (1897-2000), Hana CucherováZáveska (1902-1944) y Lilly Reich (1885-1947) -esta última compañera profesional y sentimental de Mies-, cuyas trayectorias han sido exhaustivamente estudiadas por Carmen Spegel ${ }^{17}$.

Aquí nos interesa el poder de los medios gráficos, de la prensa más especializada, que contribuyó a divulgar una cierta manera de entender la arquitectura de viviendas en USA que tuvo su continuidad con la labor del editor John Enteza y el programa Case Study House (CSH), desarrollado a lo largo de dos décadas (1945-1966) en el condado de Los Angeles (California) y que divulgó a través de la revista ArtsEAArchitectura. Este programa se considera «one of American's most significant contributions to architecture at midcentury ${ }^{18}$ y fue "Conceived as low-cost, experimental modern prototypes» ${ }^{19}$, cuyas estructuras, mayoritariamente, «incluían también elementos modulares estandarizados y estaban concebidas como prototipos para la fabricación en serie $»^{20}$. Este sumatorio de experiencias piloto está considerado, por muchos, una continuación a los grandes avances realizados en el campo de la vivienda mínima en dos frentes. Por un lado, el concurso nacional Designs for Postwar Living de 1943 patrocinado por industriales americanos y la propia revista Arts $\mathcal{E}$ Architecture ${ }^{21}$. Por otro, los logros en el entorno de la Nueva Objetividad en la Alemania de la república de Weimar entre 1924 y 1929, de los cuales, quizás, el barrio más internacional fue el experimental de la Exposición del Werkbund celebrado en Sttutgart en 1927 del que fue comisario Mies van der Rohe. Mucho de aquello que Wright y Mies tenían en común parece conjugarse en los resultados del programa CSH: jardín, espacio fluido, relación exterior-interior, modulación precisa, estructura metálica y posibilidad

17. EsPegel Alonso, Carmen. Mujeres arquitectos en el movimiento moderno. Heroínas del espacio. Valencia, Ediciones Generales de la Construcción, 2006.

18. Smith, Elizabeth A.T.; ShUlman, Julius; Goessel, Peter (ed.). The complete CSH program, 1945-1966. [1984] Cologna, ed. Taschen, 2009, p. 8.

19. Smith, Elizabeth A.T.; Shulman, Julius; GoEssel, Peter (ed.). Op. cit., p. 7.

20. Sмiтh, Elizabeth A.T. Case Study Houses, 1945-1966. El impulso californiano. Colonia, ed. Taschen, 2006, p. 23.

21. Coll Barreu, Juan. Construcción de los paisajes inventados. Los Ángeles doméstico 19001960. Barcelona, ed. Fundación Caja de Arquitectos, 2004, pp. 211-215. En 1943 se trataba del «diseño de una casa pequeña, modesta y moderna», apropiada para el fin de la guerra»; los ganadores: Saarinen y Lundquist propusieron dos módulos PAC-A y PAC-B que se complementaban y compartían un sofisticado sistema de climatización. 


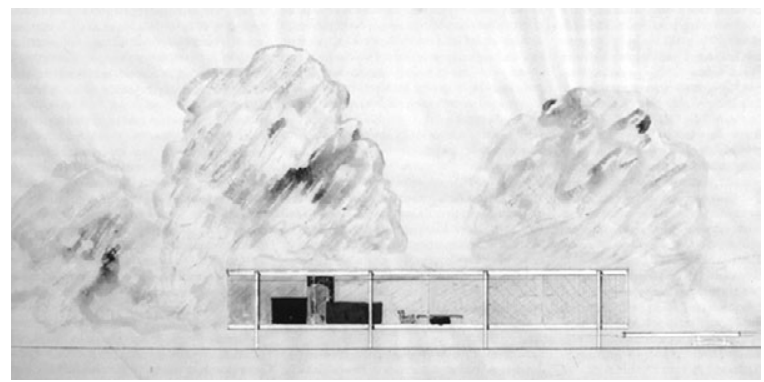

Alzado casa Farnsworth, Plano (Illinois). Mies van der Rohe (1946-51).

de estandarización de elementos para su prefabricación, entre otros, eso sí, desprendidos ya de contenido ideológico alguno. Y entre la concreción individual de las casas de Wright y la vocación de abstracción general de Mies, el programa CSH optó por la obra de autor de posibles patentes universales, como la casa 50x50 y su más ilustre antecedente: la casa Farnsworth en Plano (1946-51).

A igual que en este barrio de Sttutgart (y en toda la producción de viviendas sociales del periodo de entreguerras), los nuevos materiales y el equipamiento doméstico (que incluía sanitarios, elementos de cocina, armarios, mobiliario, luminarias) jugaban un papel determinante en la definición de la nueva vivienda - una vivienda mínima-, salvo que ahora, tras finalizar la II GM, el desarrollo de la tecnología aplicada a las máquinas del quehacer y bienestar domésticos había alcanzado una sofisticación sin precedentes. Todo había pasado a ser eléctrico y por tanto el hogar devenía electrodoméstico y automatizado, algo que la televisión ${ }^{22}$ (la primera ventana al mundo, más allá del jardín, desde el interior de las viviendas) se encargaba de divulgar en anuncios publicitarios y teleseries de ficción. Estas casas, respecto de aquellas de principios de siglo, habían reducido sus superficies, se completaban con un geométrico jardín de menor dimensión, el living se unía espacialmente al comedor y a la cocina, incluían un garaje de dos plazas y resultaban más

22. Resulta muy interesante efectuar un estudio de la relación de los modos de vivir los ámbitos domésticos y los medios de difusión de imágenes animadas, particularmente el cine y la televisión (cuyas emisiones comienzan la BBC en 1936 -en GB- y la CBS y la NBC en 1939 -USA-). También resultan instructivas las relaciones que entre Rayos $\mathrm{X}$, Mies y casas con amplias superficies de cristal que se apunta COLOMinA, Beatriz: «Visiones Borrosas. La arquitectura de la vigilancia» en ACCA (ed.). Foro Crítica. Arquitectura y Naturaleza. Alicante, ed. CTAA, 2009, p. 17: «formaron la base de la arquitectura cotidiana de mediados del siglo en los EEUU, cuando la casa transparente se convirtió en un fenómeno de masas». 


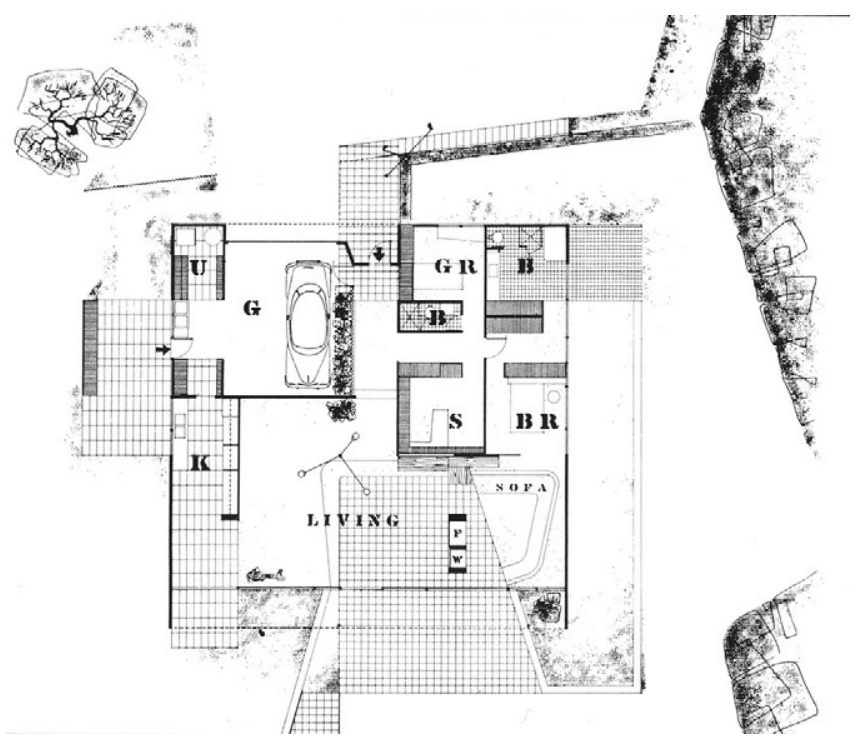

Planta casa CSH-9 (J. Enteza), Los Angeles (California). Ch. Eames y E. Saarinen (1945-49).

económicas por su estandarizada modulación. Se había definido así el que debía ser el programa de vivienda para los nuevos tiempos: «como modelo de casas pequeñas, realistas, abiertas al paisaje, higiénicas, prefabricadas, racionalistas, avanzadas ${ }^{23}$. La casa -casi siempre de una planta- se había vuelto más compacta y asequible a un mayor número de ciudadanos, sin renunciar a los tres principios que Wright había experimentado: el calor del hogar, la fluidez interior y el contacto con el jardín que, ahora, se había vuelto más un lugar de ocio, relax y diversión (incluyendo a veces piscinas), frente a aquel más estético y paisajista (con charcas y estanques).

El editor John Enteza, promotor del programa, seleccionó personalmente a los profesionales. Entre los más conocidos estaban C. Eames, R. Neutra, P. Koening y E. Saarinen; su propia casa (la CSH de 1945-49) sería proyectada por el primero y el último de la lista. No había arquitectas, pero Charles Eames trabajaba a dúo con su segunda esposa (m. 1941), la diseñadora Bernise Kaiser (1912-1988), más conocida por Ray Eames-, quien había colaborado con él y Saarinen a producir el mobiliario para la exposición «Diseño orgánico para muebles del hogar» del MoMA en 1940, con evidentes tendencias

23. Coll Barreu, Juan. Op. cit., p. 213. 
hacia la ergonomía que emana del cuerpo humano y la funcionalidad interior del espacio doméstico. En el programa también estaba Eero Saarinen, que se casaría (m. 1953) con Aline B. Louchheim (1914-1971), historiadora, editora de arte y crítica del New York Times.

De un lado, Ray se implicó de lleno en el diseño de la que sería su Casa Eames (1945-49), concebida para la «coexistencia ininterrumpida del trabajo y del ocio ${ }^{24}$, introduciendo el juego y el azar como criterios de diseño trasladados desde el ámbito de su propia vida personal y profesional. Ambos deseaban preservar los eucaliptos e integrar la casa en el paisaje porque querían «disfrutar del prado» ${ }^{25}$. Aline, sin embargo, desvinculada de este programa residencial, sería quien «gestionaba todas las relaciones públicas y diseñaba estrategias $»^{26}$ para promocionar la firma Eero Saarinen \& Associates, incluso entre los medios impresos más populares como la revista Time Magazine. Ambas mujeres, diseñadora y editora, se involucraron en contribuir a difundir el nuevo estilo de vida de la mujer, el cual conseguía liberar tiempo de sus obligaciones domésticas y familiares para dedicarlo a sus auténticas aspiraciones. Un tiempo que se arañaba gracias a los adelantos electrodomésticos y que permitía vislumbrar un nuevo modo de vida con más tiempo libre para el ocio o para el trabajo personal de cada mujer. Un genuino modo de vida que se sobrealimentaba por la publicidad televisiva y las proyecciones en cinemascope.

El efecto de este programa iría más allá de las intenciones de su promotor de la mano de su colaboradora Esther McCoy (1904-1989), editora y crítica ${ }^{27}$, especializada en la arquitectura californiana del siglo XX. Faltaban aún cuatro años para que el programa finalizase y ella recopiló una ingente cantidad de material que publicó en 1962 con el título de: Case Study Houses: 1945-1962, divulgando un particular estilo de vida expansivo y optimista, confiado en el equilibrio entre una tecnología y una naturaleza domesticadas. Su convicción de que la arquitectura californiana, en particular la de la viviendas, tenía un futuro bien cimentado en un pasado que enhebraba tradición y modernidad, ya había sido anticipado en su libro de 1960 titulado: Five California Architects; un título que sería tomado prestado una década después para titular un libro-catálogo con similares fines propagandísticos -no ajenos a la moda del

24. SмIтн, Elizabeth A.T. Op. cit., p. 23.

25. Ray Eames citada en: Koening, Gloria. Charles \& Ray Eames, 1907-78, 1912-88. Pioneros de la modernidad a mediados del siglo XX. Colonia, ed. Taschen, 2005.

26. SERRANO, Pierluigi. Eero Saarinen, 1910-1961. Un expresionista estructural. Colonia, ed. Taschen, 2005, p. 14.

27. La lista de revistas profesionales en las que colaboraba es bastante extensa; entre las más importantes citaremos: Arts \& Architecture, Architectural Forum, Architectural Record, Progressive Architecture, L'Architectura y Lotus. 
consumo de imágenes-, siendo entonces otros arquitectos los protagonistas: los Five Architects (además, situados geográficamente, en la otra costa -en la Este-, aunque lo exhibido volviera a ser lo mismo: viviendas y más viviendas).

El papel jugado por la mujer en la definición de este nuevo modo de vivir resulta significativo, máxime cuando tradicionalmente la casa ha presentado dos caras. Una exterior que entiende la casa como volumen, como posesión material y, por tanto, ligada al hombre. Otra interior, que entiende la casa como espacio, como expresión emocional y, por tanto, ligado a la mujer. Como apunta C. Espegel: «relacionar antropológicamente la casa con la construcción, y por lo tanto con el varón, en oposición al hogar, la habitación y la mujer, es un hecho histórico» ${ }^{28}$. Quizás por ello, aunque el hecho de que el interior doméstico se vuelva exterior fuese una invención básica de los arquitectos, en la consolidación del concepto de este nuevo modo de vivir -junto a una naturaleza más dominada y que proporcionaba más tiempo libre gracias a la tecnología- participaron las múltiples colaboradoras tanto en sugerencias al diseño (Catherine Ostertag y Ray Eames) como en su divulgación en imágenes fundamentalmente impresas (Aline B. Louchheim y Esther McCoy). Quizás este proceso que diluye los límites entre el interior doméstico y el exterior también pueda leerse como una muestra de la progresiva equiparación social entre la mujer y el hombre que encuentran un espacio que compartir con un mayor tiempo individual. Es obvio que en este proceso de reequilibrio -el exterior y el interior, el hombre y la mujer- jugaron un papel relevante los medios gráficos, pero más crucial aún se revelaron los medios audiovisuales - la pantalla grande y la caja tonta- como difusores de imágenes, modos de vida y roles sociales. Con toda probabilidad porque las personas somos más visuales de lo que pensamos y porque las imágenes transmiten más que meras formas.

\section{La insegura convivencia en las ciudades o el poder de la palabra}

¿La casa o la ciudad?, ¿qué fue primero? No es una pregunta que tenga una respuesta inmediata. La casa apareció para la seguridad de la vida, con su decidida vinculación a la tierra. La ciudad surgió para extender esta protección a la sociedad y garantizar la convivencia. Los poblados no resultan sólo de la agrupación de un número mínimo de viviendas. Para que resulte una ciudad es necesaria la aparición de acciones mercantiles que dinamicen las actividades de intercambio. Es consustancial la creación de una red de asentamientos en el territorio que interactúan, entre los cuales tienen lugar las

28. SPegel, Carmen. Op. cit, p. 29. 
acciones de intercambio de todo tipo de bienes. Aunque Jane Jacobs (19162006) sostuviera que «la agricultura y las técnicas de cultivo surgieron desde las ciudades ${ }^{29}$, a partir de una ficción recreada desde las investigaciones del arqueólogo británico James Mellaart en Catalhöyück (Turquía), la interpretación más aceptada es la contraria: que la agricultura fue antes que el comercio, que la casa y el poblado fueron antes que las ciudades. La original, pero ficticia, Nueva Obsidiana de Jacobs «no supone un gran desafío al <dogma de la primacía agrícola $>»^{30}$.

Sea como fuere hay un rasgo que caracteriza a las ciudades desde su nacimiento. Es la aparición de espacios públicos bien delimitados donde, como mínimo, tienen lugar las reuniones de los mercaderes (que no sólo se reúnen allí, también lo hacen en las calles que confluyen). Se trata de la plaza del mercado que todos conocen, incluso quienes no son ciudadanos del lugar. Una plaza pública que identifica a los habitantes con la ciudad. Probablemente la construcción de las ciudades arrancó muchas casas del campo y las alejó del entorno natural para configurar la obra más grande de los humanos: la ciudad. Un ser artificial que se desarrolla con las mismas pulsiones de los seres vivos que lo habitan. Ciudad y civilización tienen la misma raíz latina y el mismo género, no así la raíz sajona town que carece de género. La vita en la civitas dio origen a la civilitas, con sus registros y sus escrituras. Ciudades que tienen en su germen el fin de proteger a sus ciudadanos y garantizar la convivencia de la sociedad que albergan. Inevitablemente la distancia de sus habitantes y sus arquitecturas al medio natural de su entorno se hace mayor en la medida que la propia urbe se desarrolla, crece y se extiende. Ciudad y naturaleza parecen dos entidades contrapuestas, donde la primera niega la segunda aunque, en realidad, se sustenta sobre ella.

Por extraño que parezca, algunos periodistas - con sus obras críticas, reflexivas o propositivas- han tenido más repercusión sobre las disciplinas de la arquitectura y del urbanismo del que ni ellos mismos, ni nadie, habrían podido imaginar. Seguramente de medicina son muy pocos los que se atrevan a opinar sin ser profesionales de dicha ciencia, pero no sucede otro tanto con la arquitectura y la ciudad: a todos nos afecta y todos podemos aportar nuestro particular punto de vista. De hecho, un tema como lo urbano, con sus múltiples dimensiones, presenta entre sus especificidades el cambio continuo y el

29. JACOBS, Jane. La economía de las ciudades [1969]. Madrid, ed. Península, 1972 (original: The Economy of Cities. New York, ed. Random House, 1969).

30. MORRIS, A.E.J. Historia de la forma urbana. Desde sus orígenes hasta la revolución Industrial [1979]. Barcelona, ed. Gustavo Gili, 2006, p. 453. Este autor dedica el apéndice «D» a la teoría de Nueva Obsidiana de J. Jacobs. 


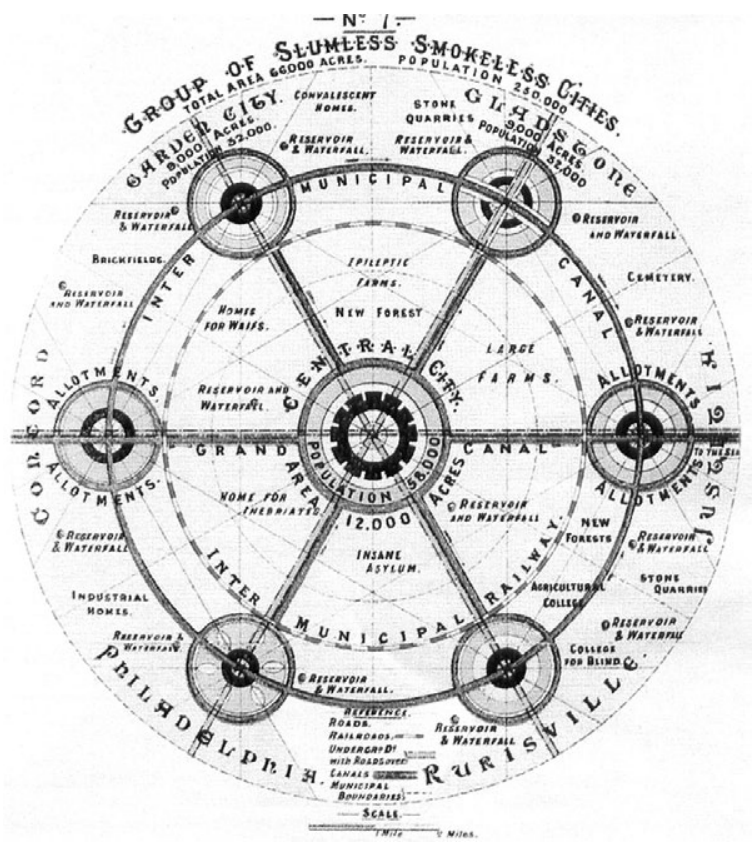

Diagrama de la ciudad jardín de Ebenezer Howard (1904).

ser objeto de estudio desde distintas perspectivas y disciplinas. Lo específicamente urbano no sólo es arquitectónico, también es público, social, económico, político, cultural, legal, paisajístico, inmobiliario y mucho más, y casi todo ello es noticia: tras la política son las cuestiones de la ciudad las que más llenan las páginas de los medios de difusión impresos o digitales. Algunas de las opiniones elaboradas por expertos de cualquiera de estas materias, o por un buen observador, se convierten en punto de arranque para otras disciplinas.

En el caso del urbanismo y la arquitectura, el libro escrito por el periodista británico Ebenezer Howard (1850-1928) supuso una revolución que daría lugar a un modo distinto de entender la convivencia en las ciudades. Fue redactado después de haber vivido en USA y haber observado con detenimiento la organización de las ciudades de aquel país y, sobre todo, las viviendas que las configuraban ${ }^{31}$. Tras su libro, Tomorrow. A Paceful Path towards

31. Para una sucinta biografía y análisis de su obra pede consultarse: BAYLEY, Stephen. La ciudad Jardín [1977]. Madrid, Adir Editores, 1982, pp: 38-43. Se señala que Howard permaneció en USA entre 1871 y 1876 trabajando como granjero y periodista. Estas 
Reform $^{32}$ (1898), surgieron las ciudades-jardín que hicieron posible que empezara a tomar cuerpo la idea de que las ciudades y la naturaleza domesticada ( «lo verde») no eran enemigas y que, por tanto, era posible un modelo de expansión (o dispersión) de las ciudades donde se estableciese un equilibrio entre lo urbano y lo rural. La influencia de sus razonamientos ${ }^{33}$ (a partir de las teorías de los tres imanes que confluían en la posibilidad de construir una ciudad que reunía las ventajas del ajetreo urbano y de la paz del campo) y de sus esquemas gráficos fueron tales que, desde entonces, casi nadie, de dentro o de fuera de las disciplinas en torno a las ciudades, cuestiona la necesidad de hacer prevalecer la presencia de la naturaleza (con el grado de artificiosidad que se requiera en cada caso) en un diálogo constante con cualquier asentamiento urbano.

A mediados del siglo XX, tanto el desarrollo desmedido de las metrópolis como la aplicación sin escrúpulos ni rigor disciplinario de los principios de la ciudad funcional -de la Carta de Atenas (1934) emanada de los CIAM- estaban dando resultados urbanos bastante desastrosos como balance general. Ciudades con los cascos históricos abandonados, barrios periféricos sin enlazar con la ciudad matriz, arquitecturas repetitivamente especulativas, carencia de equipamientos e infraestructuras básicas y, en todas ellas, la generación de espacios públicos urbanos sin ningún tipo de cualificación e incapacitados para generar identidad urbana y social. Una de las más inmediatas consecuencias de esta ciudad fragmentada y desestructurada -que no sólo se debía a las malas prácticas urbanísticas sino también a la carencia de políticas económicas y educacionales que ayudasen a cohesionar las vecindades y perfilasen un futuro de bienestar-, donde las calles y las plazas se habían diluido en un continuo espacio público indiferenciado, en una tierra de nadie salpicada por edificaciones anodinamente repetidas y de baja calidad constructiva y estética, fue el incremento de la inseguridad ciudadana simultáneo a la pérdida de la capacidad de representación de los lugares destinados al tránsito y el encuentro de los ciudadanos.

En medio de este panorama urbano surge la voz aguda de Jane Jacobs, divulgadora científica -periodista- y teórica del urbanismo, que con su libro

influencias son evidentes hasta en los términos empleados: «Central Park», «Avenues» y la numeración de las vías.

32. Este libro tuvo una edición posterior cuyo título refería directamente el modelo de ciudad dispersa: Howard, Ebenezer. Garden Cities of Tomorrow [1902]. London, ed. Faber and Faber, 1944.

33. Las propuestas de este intelectual iban más allá de lo urbano y descendieron hasta las viviendas «donde las tareas domésticas eran compartidas por una cooperativa de inquilinos» y a donde terminaría por mudarse a vivir. Véase: MuXí, Zaida. Op. cit, p. 55. 


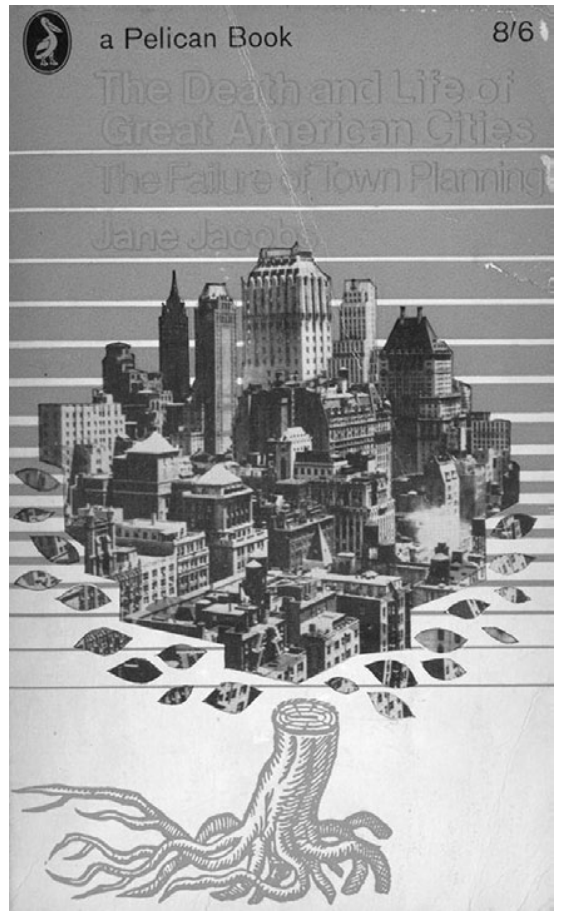

Portada del libro de J. Jacobs: Muerte y Vida de las grandes ciudades americanas (1961).

Muerte y vida de las grandes ciudades americanas ${ }^{34}$, de 1961, describió los desaciertos de la aplicación de modelos esquemáticos ideales a la planificación urbana del momento. En su discurso no deja lugar a dudas y sustituye los conceptos teóricos por las experiencias de la realidad:

$\mathrm{Al}$ exponer unos principios diferentes, me referiré esencialmente a cosas y temas perfectamente comunes y ordinarias $»^{35}$ que reafirma con decidida voluntad: «En una palabra, me referiré siempre a cosas reales, a ciudades reales y a la vida real de las ciudades $»^{36}$. Enumera los fracasos más sonados con clarividente sencillez: «los barrios de viviendas baratas se han convertido en los peores centros de delincuencia, vandalismo y desesperanza social, mucho

34. JACOBS, Jane. Muerte y vida de las grandes ciudades americanas [1961]. Madrid, ed. Península, 1973. Original: The Death and life of Great American Cities. New York, ed. Random House Inc., 1961; también disponible, parcialmente, en: <http:// abitat. aq.upm.es/boletin/n7/ajjac.html> (2010-06-23).

35. JACOBS, Jane. Muerte y vida... Op. cit.

36. Íbid. 
peores que los viejos barrios bajos que intentábamos eliminar; los proyectos de construcción de grupos de viviendas de renta media -auténticas maravillas de monotonía y regimentalización- sellaron a cal y canto las perspectivas de una vida ciudadana llena de vitalidad y dinamismo; los barrios residenciales de lujo (...) son hoy escaparates de una insípida vulgaridad; y no hablemos de los centros culturales (...) o los centros cívico-recreativos cuidadosamente evitados por todo el mundo (...); amén de los centros comerciales imitación sin lustre de lo supermercados suburbiales y de todos esos paseos que no vienen de ningún sitio y no van a ninguna parte (...); y esas autopistas que destripan las grandes ciudades» ${ }^{37}$. Concluyendo: «Esto no es reordenar las ciudades. Esto es, simplemente, saquearlas ${ }^{38}$.

Jane Jacobs, en tono irónico y guerrero, atacaba por igual a Howard y a Le Corbusier (1887-1965); al último achacaba la gran «plaga de monotonía» que observaba a su alrededor ${ }^{39}$. Identificaba las causas de la violencia en lo cotidiano de la vida urbana a una confluencia de factores entre planificación, seguridad ciudadana, calidad de vida y grado de abandono de los espacios urbanizados. Insistía en la necesidad de recuperar el contacto vecinal diario, el cual tenía lugar en las calles y en sus aceras, no en lugares indefinidos ni imprecisos: «Las calles y sus aceras son los principales lugares públicos de una ciudad, sus órganos más vitales. ¿Qué es lo primero que nos viene a la mente al pensar en una ciudad? Sus calles. Cuando las calles de una ciudad ofrecen interés, la ciudad entera ofrece interés; cuando presentan un aspecto triste, toda la ciudad parece triste ${ }^{40}$. Se anticipó, en parte, a los situacionistas como el antropólogo Marc Augé (1935), al identificar en las ciudades lo que ella llamaba «vacíos fronterizos» (ferrocarriles, autopistas, parques extensos) de dudoso beneficio ${ }^{41}$.

Su crítica radical al urbanismo imperante en los años 60 y su preocupación por redefinir el espacio público que se había vuelto un no-lugar inseguro, influyó decisivamente en toda la generación de técnicos involucrados en el planeamiento y la gestión urbanística. Se adelantó a toda la crítica que después se formalizaría en contra de la arquitectura del movimiento moderno y del urbanismo funcionalista, iniciada por Robert Charles Venturi (1925) y Denise Scott Brown (1931) en USA y por Aldo Rosi (1931-1997) en Europa; todos ellos serían autores de una serie de libros que reclamaban la capacidad

\footnotetext{
37. Íbid.

38. Íbid.

39. WATSOn, Peter. Op. cit., p. 559.

40. JACOBS, Jane. Muerte y vida... Op. cit.

41. WATSON, Peter. Op. cit., p. 560.
} 


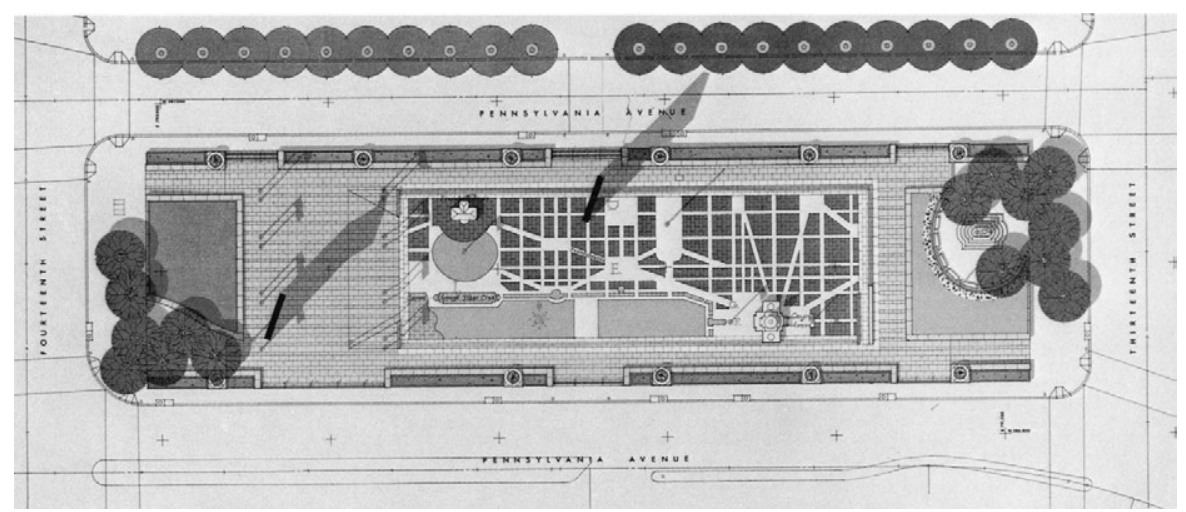

Planta de la Western Plaza, Washington DC. Venturi, Rauch y Scott (1977).

de comunicación de la arquitectura, la recuperación de un sentido consciente del pasado y la redefinición de los entornos urbanos próximos (la plaza, el jardín, el parque, la calle, la avenida, el bulevar...). Un ejemplo de la recuperación de los espacios urbanos públicos, por parte de los profesionales citados, sería la Westem Plaza en Washington D.C. (1977). Las palabras de Jacobs tuvieron como sucesoras palabras más eruditas en nuevos libros en 1966, cuya repercusión sigue resonando en las aulas de las universidades.

Sin embargo, mientras Jacobs fue aguda en su diagnosis de los problemas, a partir de la observación de la pérdida de la buena convivencia civil como consecuencia del avance de la delincuencia y la inseguridad (lo que hacía que las ciudades perdiesen su razón de ser y proliferasen los suburbios residenciales vigilados), no fue tan acertada en sus propuestas de organización y restructuración urbana. Sus cuatro principios urbanísticos (multifuncionalidad de los distritos, redimensión de las manzanas, estratificación por edades y aumento de densidades) ${ }^{42}$ constituían herramientas genéricas, poco concretas. De hecho, el problema de la convivencia urbana, de la proximidad de las relaciones, de la cercanía vecinal, era socavada por el aumento de la delincuencia, pero esta no se solucionaba sólo actuando sobre la morfología urbana y las tipologías edilicias: las soluciones requerían la convergencia de múltiples esfuerzos y políticas de los que no estaba exenta la arquitectura que definía calles que desembocaban en plazas y se abría a jardines... Sin embargo, sus ideas de autoorganización espontánea vecinal serían aplicadas con posterioridad al nuevo concepto de sistemas emergentes. Fueran cuales

42. Íbid., p. 560. 


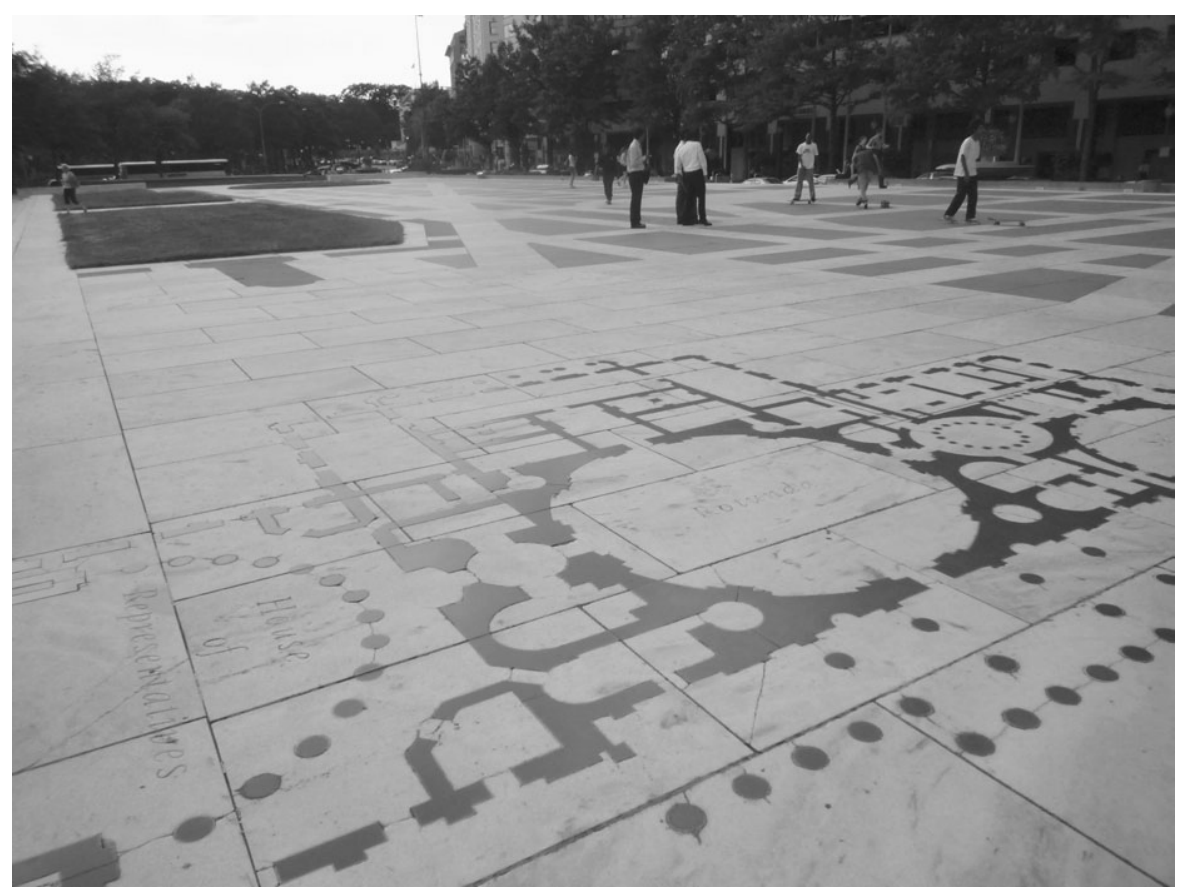

Vista de la Western Plaza, Washington DC. Venturi, Rauch y Scott (1980).

fueran sus propuestas concretas y la eficacia de las mismas, lo cierto es que el libro de Jacobs alertando del peligro de desintegración de las ciudades por falta de convivencia, fueron palabras que no cayeron en el vacío. Las palabras escritas se revelaron poderosas.

\section{Una reflexión a propósito de las protagonistas, sus armas y sus contextos}

Es obvio. Las protagonistas de este artículo no se han elegido de modo casual. No. Tampoco lo son los lugares donde vivieron y desarrollaron sus trabajos, si bien una cosa liga a la otra, aquí no hay elección. Ninguna de ellas es arquitecta, pero todas se involucraron con la arquitectura y la ciudad, los ámbitos donde se definen los roles del género. Sus esfuerzos fueron decisivos desde sus respectivas disciplinas para influir en la higiene, la vivienda y la ciudad. Florence Nightingale, británica, en el campo de la enfermería. Catherine Ostertag, Ray Kaiser, Aline B. Louchheim y Esther McCoy en el campo de lo doméstico. Y Jane Jacobs en el campo de la conveviencia. Por supuesto que 
hay más protagonistas que, comprometidas con su profesión, contribuyeron a construir una sociedad mejor y un mundo más amable, donde las personas se valoran por lo que son capaces de hacer, no por lo que se les presupone que pueden hacer o no hacer. No es extraño que todas estas protagonistas habiten países con larga tradición democrática, donde se apuesta por la libertad individual (la cual se han conquistado, no ha sido un regalo de nadie ni de nada), donde se ha favorecido la independencia económica de las personas y donde se ha implantado un sistema educativo que alcanza a más amplias capas sociales, al cual no son ajenos los medios de comunicación ${ }^{43}$ y su libertad de opinión, es decir: donde se ha fomentado una mayor libertad de prensa (y de palabra y de imágenes) y donde la competencia se fomenta como diálogo (no como imposición de criterios). Es todo un conjunto. Nada es separable. No había un destino escrito anticipado: este se ha fraguado poco a poco.

$\mathrm{El}$ artículo no pretende resolver las contradicciones de las personas. Tampoco las propias de las disciplinas de la arquitectura y la ciudad. A veces resulta incompatible defender un determinado tipo de arquitectura (y de espacio doméstico vinculado a la naturaleza domesticada y próxima) con una ciudad que no esté diseminada o dispersa. En algún momento lo hemos avanzado: ciudad y naturaleza son dos entidades contrapuestas, pero una necesita de la otra. No se trata de una dependencia mutua y correspondida, a diferencia de la relación que se establece entre arquitectura, ciudad y sociedad: nos resulta muy difícil imaginarlas cada una por separado. Sólo se pretende poner de relieve dos cuestiones. La primera es que las influencias y avances en una materia no siempre proceden del interior, apostando por la interdisciplinaridad e interacción del conocimiento entre disciplinas próximas o, en apariencia, lejanas, por lo que han sido posibles las aportaciones de mujeres a materias en las que, en su época, difícilmente ostentaban responsabilidad profesional directa. En su momento las mujeres no eran enfermeras formadas, arquitectas o urbanistas y, sin embago, desde territorios afines influyeron decisivamente aportando sus experiencias y puntos de vista. La segunda es que el protagonismo alcanzado por mujeres siempre ha resultado más posible en aquellos países que dificultaban menos sus ansias por hacerse valer como profesionales

43. WATSON, Peter. Op. cit., p. 241, señala que: «El historiador J.H. Plumb (1911-2001) ha señalado que uno de los logros no reconocidos del siglo XX ha sido la formación cultural de un vasto número de personas. Esto ha sido posible gracias a las escuelas y universidades subvencionadas por el gobierno, pero también a los nuevos medios de comunicación, muchos d elos cuales tuvieron su incio en los años veinte». Y se refiere explícitamente a las revistas de difusión masiva, la radio, el cine, la televisión e internet. 
de una determinada materia, en lugar de tiranizar a las personas considerándolas por igual, de bien o de mal; es decir: permitía vías para la realización profesional aunque esta no estuviera exenta de dificultades.

En nuestro caso, Florence Nightingale se valio de su perseverancia y sus dotes de observación de las condiciones espaciales y materiales que rodeaban la vida de los enfermos. Estos datos los transformó en cifras que reflejó en tablas que resultarían estadísticas y le dieron las pistas de cómo mejorar las instalaciones hospitalarias con lo que ella denominó las leyes de la salud o la higiene. Los números le dieron la confirmación de sus deducciones experimentales. En segundo lugar, Catherine Ostertag y Ray Eames colaboraron a diseñar viviendas que apostaban por abrir el interior de la vivienda horizontal al exterior ajardinado, disolviendo los límites de lo doméstico para ganar espacio para sus ocupaciones y tecnificando las tareas domésticas que liberaban tiempo para sus aspiraciones. Esta tarea del proyecto fue compartida con los hombres, como no podía ser de otro modo. Mientras que Aline B. Louchheim y Esther McCoy se hicieron cargo de divulgar y difundir este singular modo de vida californiano -no exento de contradicciones-, para el que resultaron decisivas las aportaciones de los medios de comunicación audiovisuales como el cine y la televisión. Por último, Jane Jacobs, tras su estudio y análisis de las ciudades americanas, constató la degradación de la convivencia en las mismas a consecuencia de la creciente delincuencia que achacó a la deficiente planificación vigente. Sus palabras, más que sus propuestas, sirvieron para que la comunidad de expertos empezase a mirar la ciudad de otro modo y fuese capaz de ir encontrando soluciones parciales a la complejidad del problema urbano. Tanto en la higiene, en la vivienda como en la ciudad, siempre está presente la Naturaleza. «Naturaleza se escribe con 'N' mayúscula» que diría Wright para quien «La Naturaleza es todo lo que llegaremos a conocer del cuerpo de Dios» ${ }^{44}$.

Así pues, números, imágenes y palabras se convirtieron en armas para hacer valer las ideas de mujeres profesionales en los ámbitos de la higiene, la vivienda y la ciudad, demostrando su validez, sino universal, sí, al menos, particular para su momento y los problemas allí planteados. Números, imágenes y palabras que son armas del diálogo y del convencimiento y que podemos usar mujeres y hombres por igual. Compartimos, pues, la visión del historiador Herbet Butterfield (1900-1979), según la cual no hay necesidad de emitir juicios morales, por lo que no pretendemos juzgar el pasado desde

44. Frank Lloyd Wright citado por: BROOKS PFEIFFER, Bruce. Frank Lloyd Wright [1991]. Cologne, ed. Taschen, 2007, p. 28. 
el presente, porque las grandes luchas del pasado no se han dado entre un bando de «buenos»y otro de «malos» $»^{45}$. A lo sumo que aspiramos es a haber contribuido a la construcción con más detalle de nuestra historia, porque el pasado sucede, pero la Historia se construye.

\section{Referencias bibliográficas}

Attewell, Alex. «Florence Nightingale (1820-1910)». Perspectivas: revista trimestral de educación Comparada, vol. XXVIII, nº 1, (1998), París, pp. 173-189.

BACHELARD, Gaston. La poética del espacio [1957]. México, ed. Fondo de Cultura Económica, 2010.

BAYLEY, Stephen. La ciudad Jardín [1977]. Madrid, Adir Editores, 1982.

BROOKS PFEIFFER, Bruce. Frank Lloyd Wright [1991]. Cologne, ed. Taschen, 2007, p. 28.

Coll Barreu, Juan. Construcción de los paisajes inventados. Los Angeles doméstico 1900-1960. Barcelona, ed. Fundación Caja de Arquitectos, 2004.

ColominA, Beatriz: «Visiones Borrosas. La arquitectura de la vigilancia» en ACCA (ed.). Foro Crítica. Arquitectura y Naturaleza. Alicante, ed. CTAA, 2009.

ESPEGEL AlONSO, Carmen. Mujeres arquitectos en el movimiento moderno. Heroinas del espacio. Valencia, Ediciones Generales de la Construcción, 2006.

FRAMPTON, Kenneth. Historia crítica de la arquitectura moderna [1980]. Barcelona, ed. Gustavo Gili, 1998.

HOwARD, Ebenezer. Garden Cities of Tomorrow [1902]. London, ed. Faber and Faber, 1944.

INFANTINO, Lorenzo. El orden sin plan. Las razones del individualismo metodológico [1998]. Madrid, Unión Editorial, 2000.

JACOBS, Jane. Muerte y vida de las grandes ciudades americanas [1961]. Madrid, ed. Península, 1973; también disponible, parcialmente, en <http:// abitat.aq.upm. es/boletin/n7/ajjac.html> (2010-06-23).

KoENING, Gloria. Charles \& Ray Eames, 1907-78, 1912-88. Pioneros de la modernidad a mediados del siglo XX. Colonia, ed. Taschen, 2005.

LE CORBUSIER. Hacia una arquitectura [1923]. Barcelona, ediciones Apóstrofe, 1998, p: XXXI.

MORRIS, A.E.J. Historia de la forma urbana. Desde sus orígenes hasta la revolución Industrial [1979]. Barcelona, ed. Gustavo Gili, 2006.

MuXí, Zaida: «Decir la ciudad desde la experiencia». Arquitectos, n 2, (2006), Madrid, pp. 53-58.

PeVSNER, Nikolaus. Historia de las Tipologías Arquitectónicas [1976]. Barcelona, ed. Gustavo Gili, 1979.

45. WATSON, Peter. Op. cit., p. 278.

Feminismo/s 17, junio 2011, pp. 229-257 
SERrano, Pierluigi. Eero Saarinen, 1910-1961. Un expresionista estructural. Colonia, ed. Taschen, 2005.

Smith, Elizabeth A.T. Case Study Houses, 1945-1966. El impulso californiano. Colonia, ed. Taschen, 2006.

Smith, Elizabeth A.T; Shulman, Julius; Goessel, Peter (ed.). The complete CSH program, 1945-1966 [1984]. Cologna, ed. Taschen, 2009.

Watson, Peter. Historia intelectual del siglo XX [2000]. Barcelona, ed. Crítica, 2007.

Zabalbeascoa, Anatxu; Rodríguez Marcos, Javier. Vidas construidas, biografías de arquitectos. Barcelona, ed. Gustavo Gili, 1998. 